NASA Technical Memorandum 106856

AIAA-95-1944

$17030 /$
$p-9$

Electrostatic Noise in the Plasma Environment Around the Shuttle

Boris V. Vayner and Dale C. Ferguson

Lewis Research Center

Cleveland, Ohio

Prepared for the

26th Plasmadynamics and Lasers Conference

sponsored by the American Institute of Aeronautics and Astronautics

San Diego, California, June 19-22, 1995

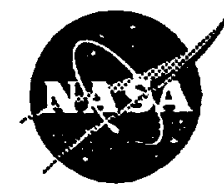

National Aeronautics and Space Administration

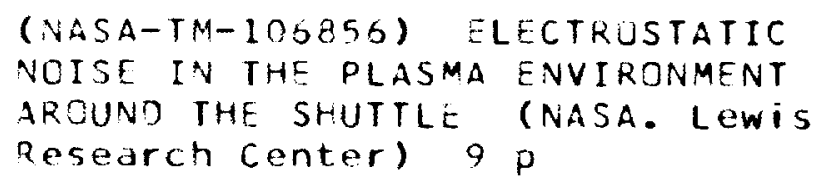




\title{
ELECTROSTATIC NOISE IN THE PLASMA ENVIRONMENT AROUND THE SHUTTLE
}

\author{
Boris V. Vayner* and Dale C. Ferguson " \\ National Aeronautics and Space Administration \\ Lewis Research Center, Cleveland, Ohio 44135
}

\begin{abstract}
The Langmuir probe flown as a part of the SAMPIE package aboard the space shuttle flight STS-62 was used to determine plasma potential fluctuations in the vicinity of the shuttle. The broadband noise was observed at frequencies 250-20,000 Hz. Measurements were performed in ram conditions; thus, it seems reasonable to believe that the influence of spacecraft operations on plasma parameters was absolutely negligible. The average spectrum of fluctuations is in agreement with theoretical predictions. The influence on the observed spectra of arcing generated by high negative bias voltages applied to solar cell samples is briefly discussed.
\end{abstract}

\begin{tabular}{|c|c|}
\hline & Nomenclature \\
\hline & magnetic field strength \\
\hline$D(\omega)$ & observed spectrum \\
\hline$f$ & $\begin{array}{l}\text { frequency of plasma density } \\
\text { fluctuations }\end{array}$ \\
\hline$I, i$ & LP current \\
\hline . & wave vector \\
\hline$J_{0}(\alpha)$ & Bessel function \\
\hline $\mathrm{n}_{\mathrm{e}}$ & electron number density \\
\hline $\mathrm{n}_{\mathrm{i}}$ & ion number density \\
\hline $\mathrm{N}_{\mathrm{arc}}$ & number of arcs per one experiment \\
\hline$t$ & time \\
\hline$T_{e}$ & electron temperature \\
\hline $\mathrm{U}$ & output voltage \\
\hline $\mathrm{V}$ & spacecraft velocity \\
\hline$x$ & vector of spatial coordinates \\
\hline
\end{tabular}

"National Research Council-NASA Research Associate at Lewis Research Center.

†Physicist, Space Environment Effects Branch

\author{
$\delta(x, t)$ amplitude of plasma density \\ fluctuations \\ $\Phi \quad$ angle between velocity vector \\ and $z$ axis \\ $\mu \quad$ azimuthal angle of wave vector \\ $\Theta \quad$ angle between wave vector and \\ $z$ axis \\ $\tau_{\exp } \quad$ duration of individual experiment with \\ arcing \\ $\tau_{\text {dwe11 }} \quad$ duration of one dwell \\ $\omega$ wave frequency

\section{Introduction}

As a part of the SAMPIE (The Solar Array Module Plasma Interactions Experiment) program, the Langmuir probe (LP) was employed to measure plasma characteristics during the experiment ${ }^{1}$. The whole set of data could be divided into two parts: i) low frequency sweeps to determine voltage-current characteristics and to find electron temperature and number density; ii) high frequency turbulence (HFT dwells) data caused by electrostatic noise. It is known that spacecraft operations influence LP data ${ }^{2}$. To provide measurements of plasma density fluctuations caused by turbulence in the LEO plasma itself, we analyze LP data that were obtained in ram conditions only. According to purposes of SAMPIE, the samples of solar cells were placed in the cargo bay of the shuttle, and high negative bias voltages were applied to them to initiate arcing between these cells and surrounding plasma. The arcing onset was registered by special counters, and data were obtained that included the amplitudes of current, 
duration of each arc, and the number of arcs per one experiment. This organization of the experiment allows analysis of the L.P data (HFT) for two different situations: i) with arcing on samples of solar cells; ii) without arcing. HFT data were obtained during the dwells lasting for $4 \mathrm{~ms}$ each, and experimental data were represented in digital form: 80 points with $50 \mu \mathrm{s}$ intervals. This means that we are able to study the spectra of plasma turbulence within the narrow frequency interval $\Delta f=250-10,000 \mathrm{~Hz}$. We may suggest that there is an influence of arcs on HFT data. This influence could be caused by changes in plasma parameters as well as fluctuations of spacecraft potential. Electrostatic noise spectra for both situations (with arcing and without arcing), analysis of correlation properties of different signals, and the preliminary theoretical explanation of the observed differences of these spectra will be discussed below.

\section{Plasma parameters}

The electron number density and electron temperature were obtained during sweeps that lasted for $4 \mathrm{~s}$ each. During this time interval the bias voltage on LP was changed twice: down from $+10 \mathrm{~V}$ to $-5 \mathrm{~V}$, and up from $-5 \mathrm{~V}$ to $+10 \mathrm{~V}$. An example of the sweep data is shown in Fig.1. The current flowing throughout the LP can be calculated according to the following formula: ${ }^{3}$

$I=\exp (1.0226 \mathrm{U}-9.3866) \mathrm{mA}$

where $U$ is output voltage on the OP amplifier.

Thus, changes of electron number density and electron temperature were registered for ram conditions: $\mathrm{n}_{\mathrm{e}}=(5-80) \times 10^{5} \mathrm{~cm}^{-3}$ and $T_{e}=0.05-0.3 \mathrm{eV}$. It should be noted that the magnetic field strength changed within a narrow range $B=0.25-0.5$ Gs during the flight, and the angle between the spacecraft velocity and magnetic field vector changed from $-60^{\circ}$ to $80^{\circ}$. The variations in the basic plasma characteristics caused variations in such important plasma parameters as electron and ion plasma frequencies, Debye length, Alfven velocity, and the speed of ion acoustic waves (IAW). For our purposes it seems convenient to represent all of these parameters in the form of simple formulae in Table 1, below.

Table 1

Electron Langmuir frequency

Ion Langmuir frequency (for ions $\mathrm{O}^{+}$)

Debye length

Alfven velocity

Speed of Ion Acoustic Waves

Electron gyrofrequency

Ion gyrofrequency

Lower hybrid frequency

$$
\begin{aligned}
& f_{e}=9 \sqrt{\frac{n_{e}}{10^{6} \mathrm{~cm}^{-3}}} \mathrm{MHz} \\
& f_{i}=56 \sqrt{\frac{n_{i}}{10^{6} \mathrm{~cm}^{-3}}} \mathrm{kHz} \\
& D_{e}=0.3\left(\frac{T_{e}}{3000 K}\right)^{0.5}\left(\frac{n_{e}}{10^{6} \mathrm{~cm}^{-3}}\right)^{-0.5}-\mathrm{cm} \\
& W_{A}=2.7 \cdot 10^{7}\left(\frac{B}{0.5 G s}\right) \cdot\left(\frac{n_{e}}{10^{6} \mathrm{~cm}^{-3}}\right)^{-0.5} \mathrm{~cm} / \mathrm{s} \\
& W_{s}=1.27 \cdot 10^{5}\left(\frac{T_{e}}{3000 K}\right)^{0.5} \mathrm{~cm} / \mathrm{s} \\
& f_{H}=1.4 \cdot \frac{B}{0.5 G s} \quad \mathrm{MHz} \\
& F_{H}=48 \cdot \frac{B}{0.5 \mathrm{Gs}} \quad \mathrm{Hz} \\
& f_{L H}=8.2 \cdot \frac{B}{0.5 \mathrm{Gs}} \quad \mathrm{kHz}
\end{aligned}
$$


To analyze the LP data, particularly HFT dwells, we should take into account the motion of spacecraft through the surrounding plasma.
The Fourier integral for fluctuations of the plasma density can be written in the following form:

$\delta(x, t)=\int \delta(k, \omega) \cdot \exp (-i \cdot \omega \cdot t+i \cdot k \cdot(x-V \cdot t)) \cdot d \omega \cdot d^{3} k=$

$$
\begin{aligned}
& \int_{0}^{\infty} d \omega \int_{0}^{\infty} k^{2} d k \int_{0}^{\pi} \sin \theta \cdot d \theta \int_{0}^{2 \pi} d \mu \cdot \delta(k, \omega) \cdot \exp (-i \cdot \omega \cdot t+i \cdot k \cdot x \cdot \cos \theta-i \cdot k \cdot V \cdot t \cdot \cos \Phi \cdot \cos \theta) \\
& \exp (-i \cdot k \cdot V \cdot t \cdot \sin \Phi \cdot \sin \theta \cdot \cos \mu)
\end{aligned}
$$

Finally, after performing some simple algebra, we can write the observed frequency spectrum in the form:

$$
D(\Omega)=4 \cdot \pi \cdot \int_{0}^{\sigma} k^{2} d k \cdot \int_{0}^{\infty} d \omega \cdot \delta(k, \omega) \cdot \int_{0}^{\infty} d t \cdot \frac{\sin k V t}{k V t} \cdot \exp (i \Omega t-i \omega t)
$$

To obtain the Eq. (3) we suggest LP is placed in the point $x=0$ of the coordinate system.

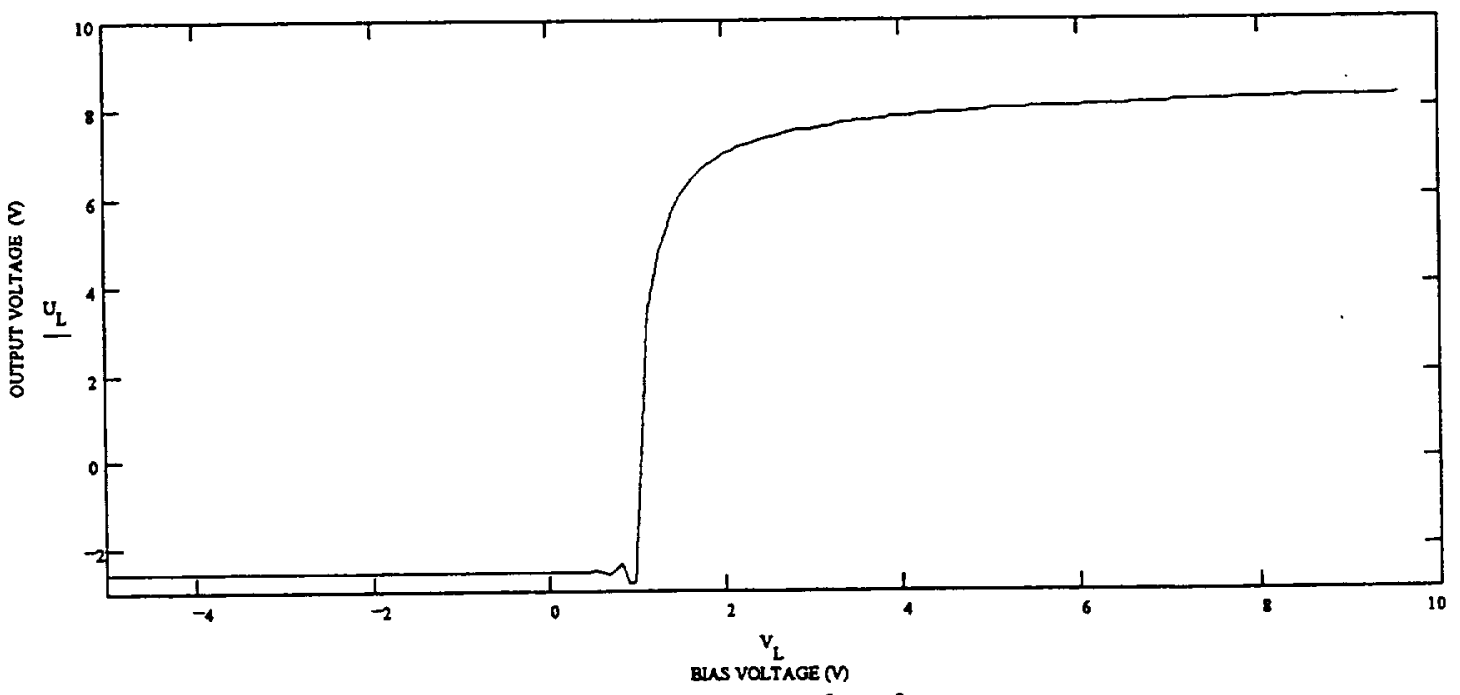

Fig.1. Langmuir characteristic for density $n_{4}=10^{6} \mathrm{~cm}^{-3}$

It is easy to see that the major contribution to the integral (3) is provided by two shifted frequencies $\Omega_{1,2}=\omega \pm k V$. For Ion Acoustic waves (IAW) within the frequency interval $E_{H}<f<f_{L H}$, the wave numbers can be estimated as $\mathrm{k}=2 \pi \mathrm{fW}_{\mathrm{s}}{ }^{-1}=0.0002-0.4$ $\mathrm{cm}^{-1}$, and the following inequality is fulfilled always: $\mathrm{kD}_{\mathrm{e}} \ll<1$. This implies that the temporal attenuation rate of IAW is very small: ${ }^{4}$

$$
\frac{\gamma}{f}=2 \cdot \pi \cdot\left(\frac{\pi \cdot m_{e}}{8 \cdot m_{i}}\right)^{0.5} \ll 1
$$


Expression (4) is valid for almost all waves except waves that propagate perpendicularly to magnetic field. Of course, IAW are attenuated due to absorption by ions on frequencies $f \geq f_{i}$.

\section{Observations}

As was mentioned above we possess data obtained by the LP for two different situations : with arcing and without arcing. One example of an HFT dwell is shown in Fig.2. One can see that the amplitude of current flow reaches the value $i_{\max }=0.155 \mu \mathrm{A}$, and the average value is equal to $i_{\text {ave }}=0.076 \mu \mathrm{A}$. The electron number density fluctuations can be estimated according to the following equation:

$\delta=\frac{\delta n_{e}}{n_{e}} \approx \frac{i_{\max }}{I_{\text {sat }}}$

The saturation current was equal to $I_{\text {sat }}=300$ $\mu$ A (Fig. 1). Thus, the amplitude of fluctuations is $\delta=5 \times 10^{-4}$. The spectrum of this signal is shown in Fig. 3. The sharp decline of amplitude for frequencies $f>6.5 \mathrm{kHz}$ is seen very clearly. The average spectrum was built using data of twelve dwells (Fig.4). No peculiarities can be established in this average spectrum. Figure 5 illustrates the signal that was registered when arcs occurred. First of all, it is seen that there is a significant difference in amplitudes between signals with arcing and without them. For this dwell, the amplitude of current fluctuations is as large as $2 \mu \mathrm{A}$. Moreover, the average spectrum that had been calculated by using data of twelve dwells with arcing is almost flat for frequencies $f>500 \mathrm{~Hz}$. We did not find correlations between plasma parameters and spectral characteristics either for dwells with arcing or dwells without arcing. However, the peak current depends on number of arcs rather strongly (Fig.6). We believe that the large amplitude of LP current is caused by changes in the spacecraft potential due to arcing. When arcing occurs, the difference of potentials between the shuttle and the surrounding plasma changes $\Delta V \approx 2-3 \quad V$ for the moment of each arc. Because the duration of each arc is equal to $0.1-0.5 \mu \mathrm{s}$, the measured value of $L P$ current can be estimated as

$\Delta I_{\max }=\frac{N_{\text {arc }}}{\tau_{\exp }} \cdot \tau_{\text {dwell }} \cdot\left(\frac{a_{\text {sat }}}{\partial V} \cdot \Delta V\right)$

For example, during one experiment there were $N_{\text {arc }}=1500$, the duration of the experiment $\tau_{\text {exp }}=60 \mathrm{~s}$, and $\tau_{\text {dwell }}=4 \mathrm{~ms}$. The value of the expression in the parenthesis can be obtained from appropriate sweep data (Fig.1). The result of the calculation, $\Delta \mathrm{I}_{\max } \approx 2 \mu \mathrm{A}$, is in agreement with the measurements.

\section{Conclusion}

According to theoretical considerations the spectrum of noise in the ionospheric plasma should have the following form: ${ }^{4}$

$D(f)=\frac{A}{f} \cdot F\left(\frac{f}{f_{e}}\right)$

where $A=$ Const, and $F(f)$ is a slow function of frequency. In reality, we obtained

$D(f) \propto f^{-0.76 \pm 0.2}$ for the average spectrum without arcing, in agreement with expectations.

Electrostatic noise with such parameters was observed early ${ }^{2}$, and those authors suggested that there were IAW generated in the vicinity of the lower hybrid resonance and shifted due the Doppler effect by $\Delta f=2-3 \mathrm{kHz}$. Moreover, they proved that the reason for the IAW instability was the so called "ring distribution" of water ions that were sublimated from spacecraft surfaces. These last conclusions were based on the data obtained by the Plasma Diagnostic Package (PDP) operating in wake of the shuttle (advanced analysis and new data are published in Ref.5,6).

We see from the present work that fluctuations with a broad spectrum are developed in the plasma itself. It might be suggested that the reason for their generation and instability exists in the surrounding medium (convective flows, solar cosmic rays, or something else). More measurements of LP current fluctuations should be done in ram conditions to understand the nature of the observed electrostatic noise. It seems particularly important to measure fluctuations at frequencies up to $60 \mathrm{kHz}$ where attenuation due to absorption by ions at the ion plasma frequency is practically negligible. 


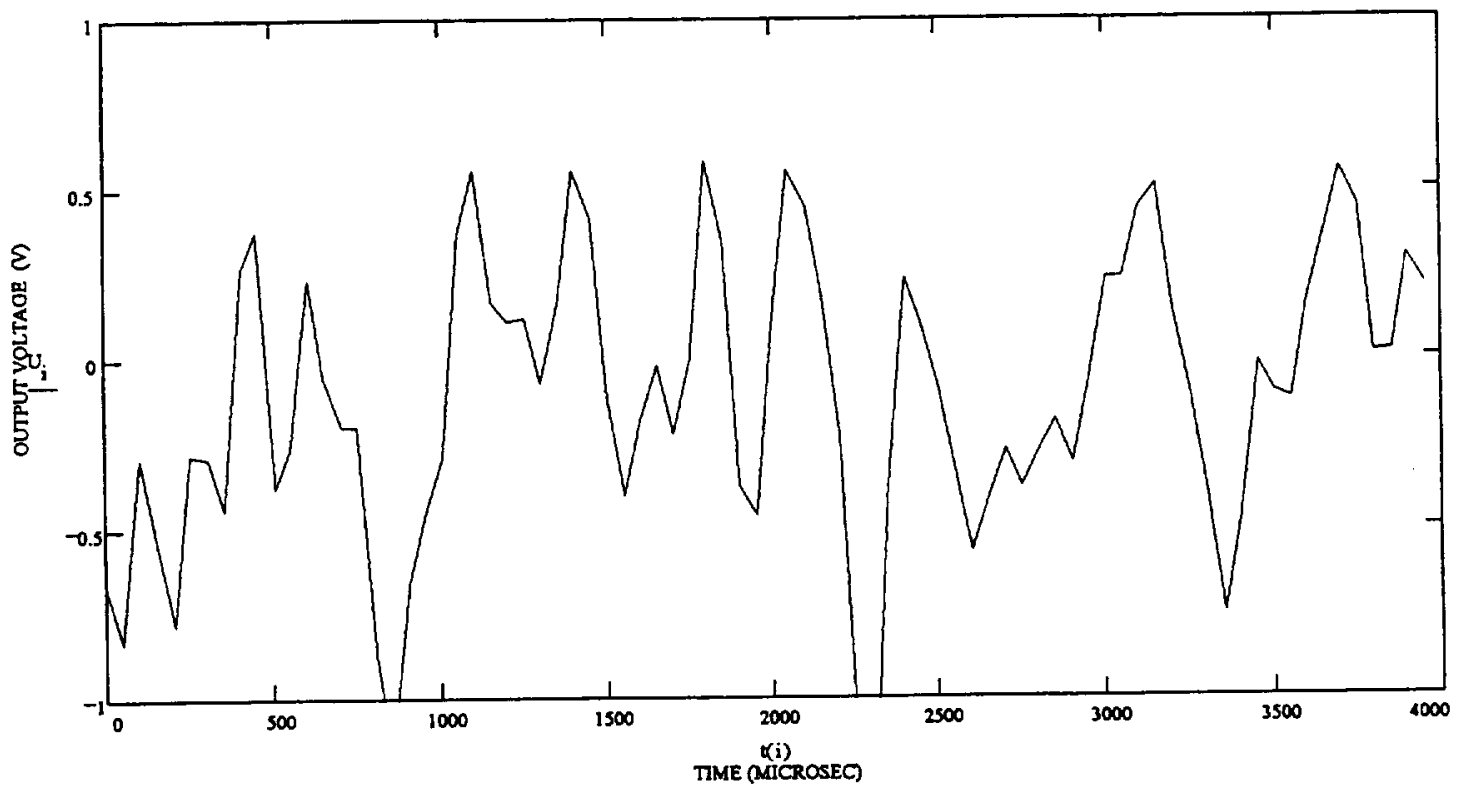

Fig.2 LP output voltage fluctuations measured during a dwell in ram conditions (MET 23:39:47)

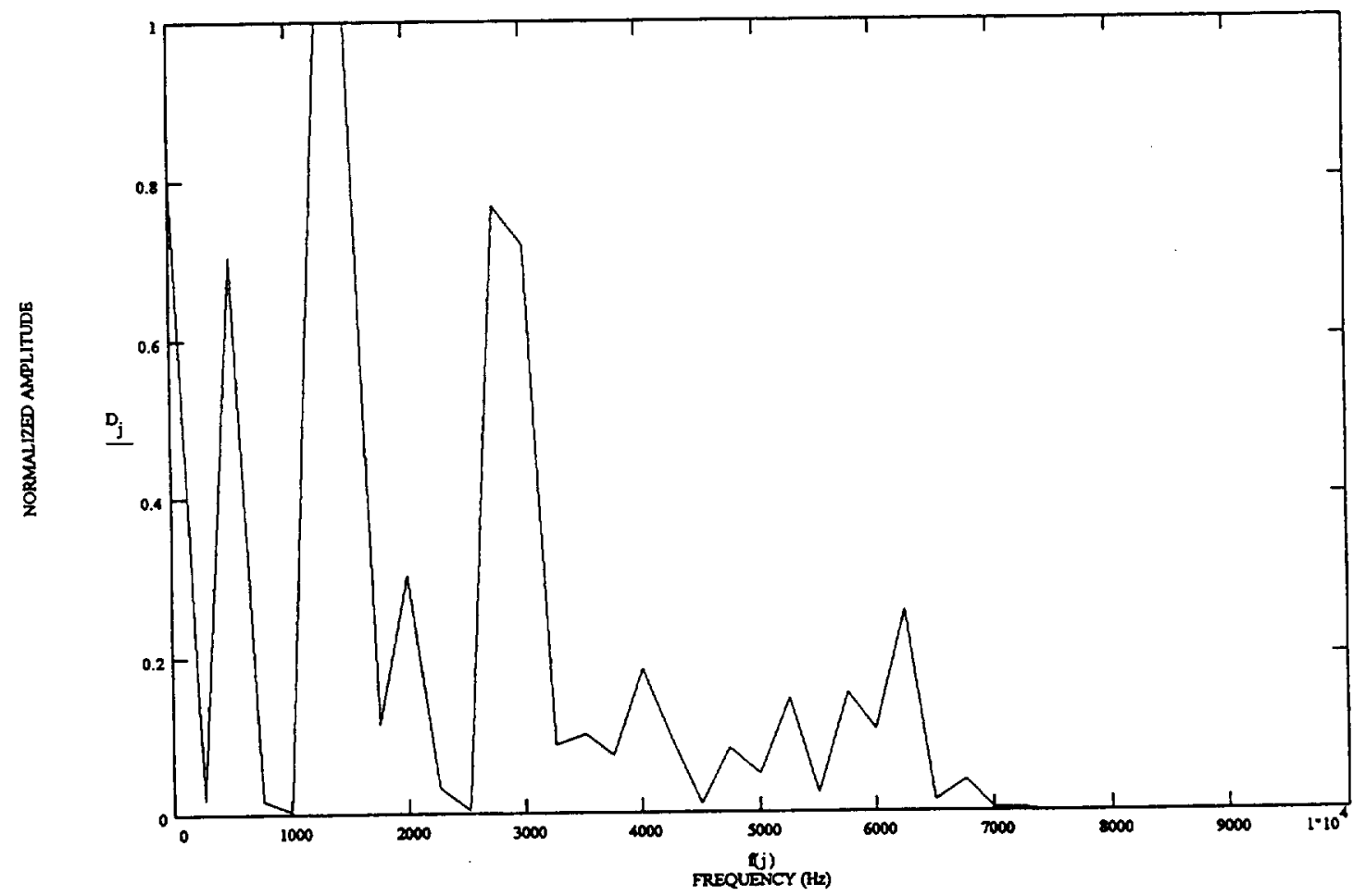

Fig.3. Spectrum of fluctuations that are shown above. The sharp decline for $\$ 6.5 \mathrm{kHz}$ is seen very well. 


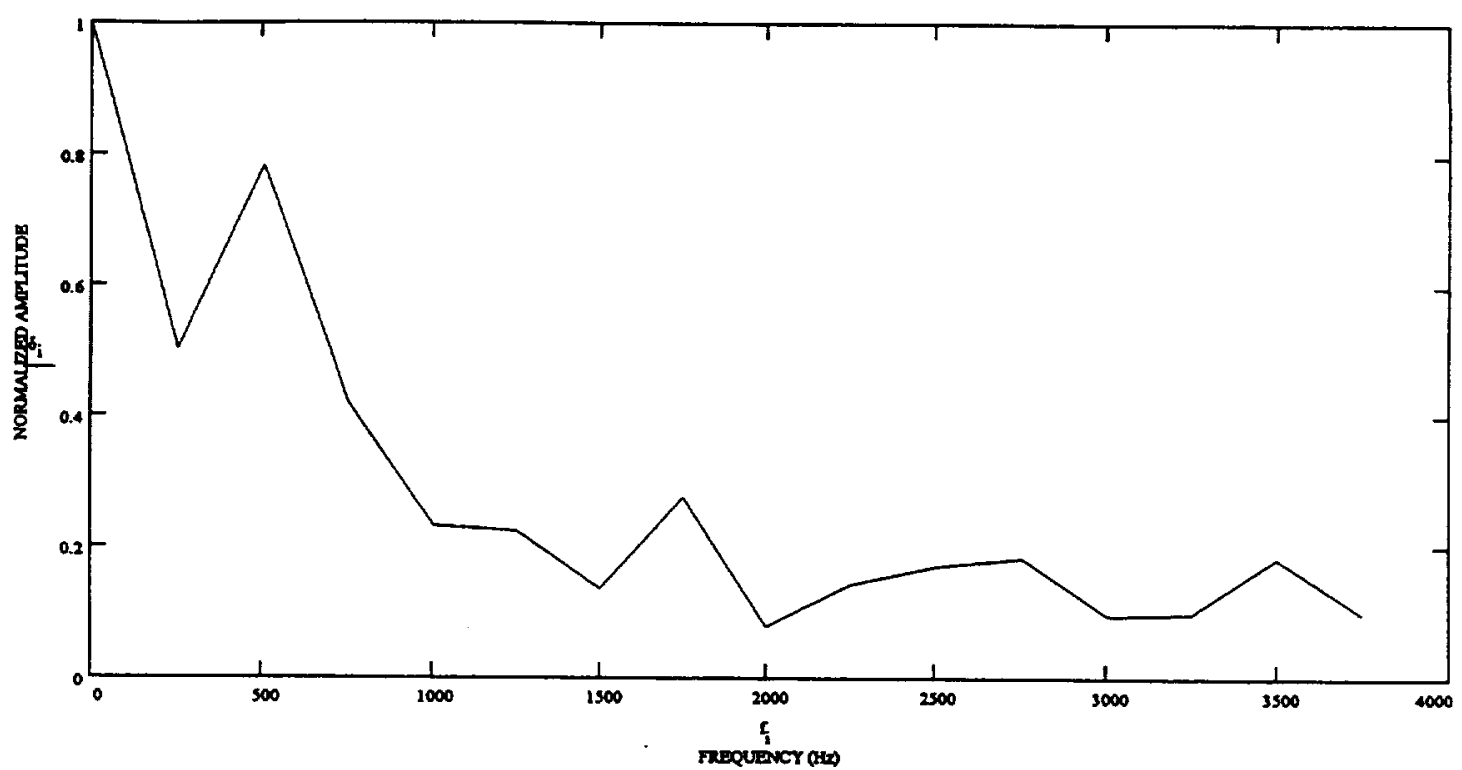

Fig.4. Average spectrum that was build by using data from twelve dwells. The best fit approximation $\delta \propto<\mathrm{f}^{0.76 \pm 0.2}$ is in good agreement with theoretical predictions.

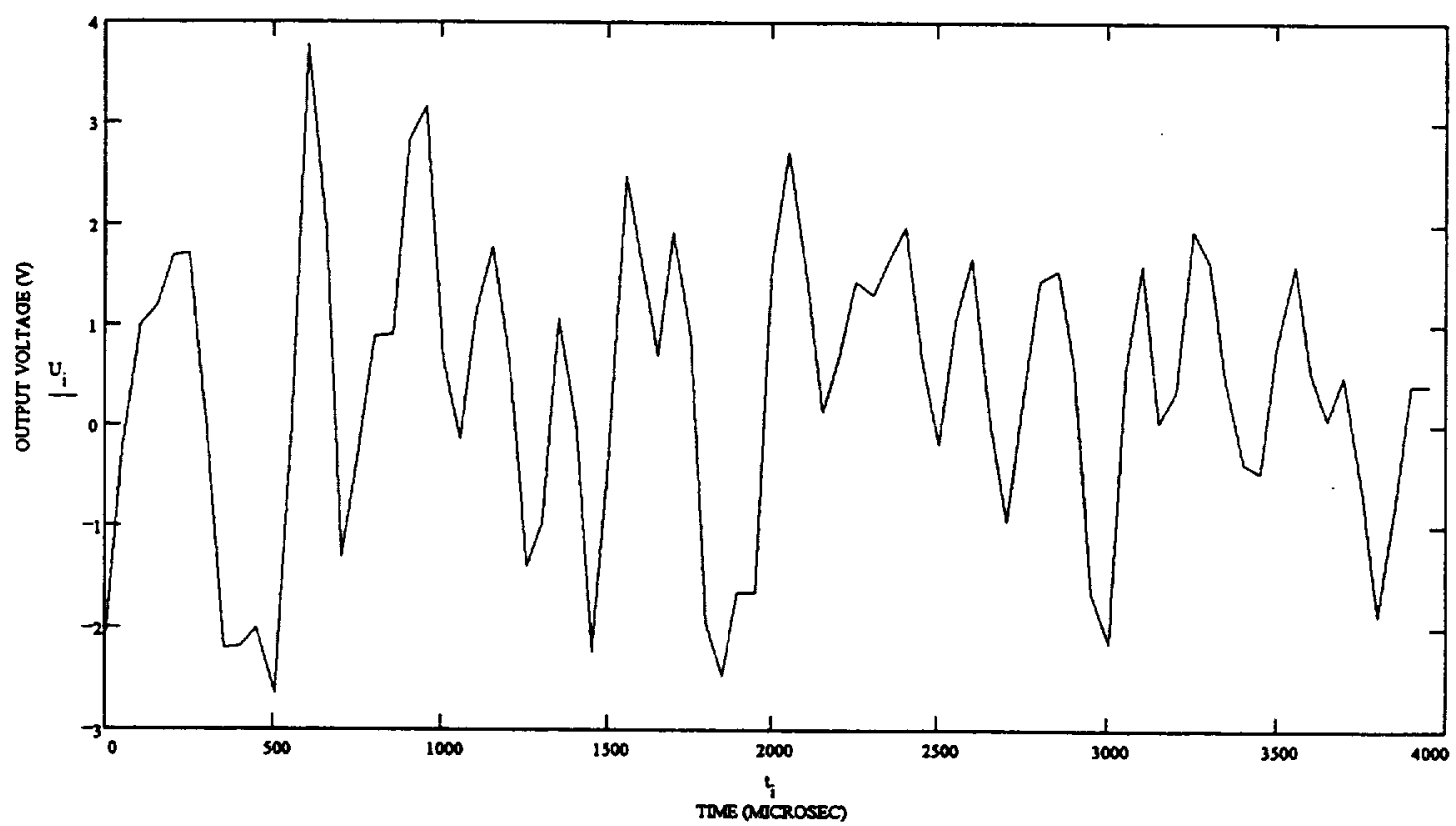

Fig.5. LP output voltage fluctuations measured during the dwell in ram conditions when arcing occurred (MET 17:21:40). This plot demonstrates the large amplitude caused by arcing. 


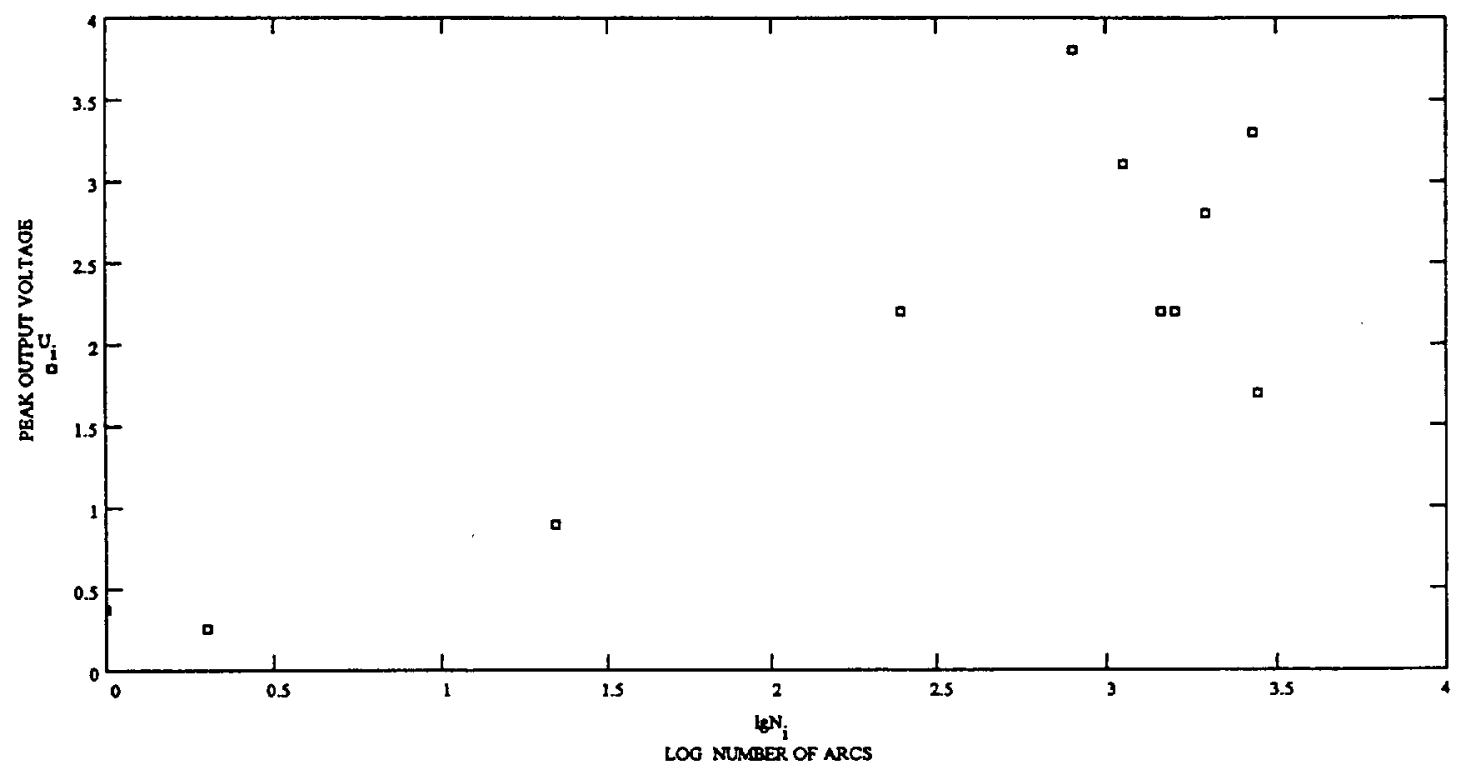

Fig.6. LP peak voltage vs. the number of arcs per one experiment. Twelve dwells are used to draw this chart. No correlations were found between the peak voltage and the distance of the LP from biased solar cell samples.

\section{Acknowledgments}

This work was performed while B.V. Vayner held a National Research Council -NASA/LRC Research Associateship.

\section{$\underline{\text { References }}$}

${ }^{1}$ Hillard, G.B., and Ferguson, D.C., 'Solar Array Module Plasma Interactions Experimant (SAMPIE)", Joumal of Spacecraft and Rockets, Vol.30, No 4, 1993, pp. 488-494

${ }^{2}$ Murphy, G., Pickett, J., D'Angelo, N., and Kurth, W.S. "Measurements of Plasma Parameters in the Vicinity of the Space Shuttle", Planet. Space Sci., Vol.34, No 10, 1986, pp. 993-1004.

${ }^{3}$ Bozich,R, and Stung, $D$., private communication, 1994

${ }^{4}$ Al'pert, Ya.L. 'Space Plasma", Vol. I, 1990, Cambridge University Press, $308 \mathrm{p}$.

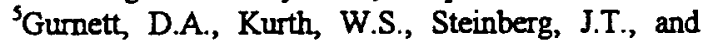
Shawhan, S.D., 'Plasma Wave Turbulence Around The Shuttle: Results From The Spacelab-2 Flight", Geophysical Research Letters, Vol.15, No 8, 1988, pp.760-763.

'Pickett, J.S., D'Angelo, N., and Kurth, W.S., 'Plasma Density Fluctuations Observed During Space Shuttle Orbiter Water Releases", Joumal of Geophysical Research, Vol.94, No A9, 1989, pp. $12,081-12,086$ 
Public reponting burden for this coltection of information is estimated to average 1 hour per response, including the time for reviewing instructions, searching existing data sources, gathering and mainaining the data needed, and completing and reviewing the collection of information. Send comments regarding this burden estimate or any other aspect of this collotion of information, including sugestions for reducing this burden, to Washington Headquanters Services. Directorate lor Information Operations and Reports, 1215 Jellerson Davis Highway, Sulte 1204. Arlington, VA 22202-4302, and to the Ottice of Management and Budget, Papenwork Reduction Project (0704-0188), Washington, DC 20503.

\begin{tabular}{|l|c|c|}
\hline 1. AGENCY USE ONLY (Leave blank) & $\begin{array}{c}\text { 2. REPORT DATE } \\
\text { February 1995 }\end{array}$ & $\begin{array}{r}\text { 3. REPORT TYPE AND DATES COVERED } \\
\text { Technical Memorandum }\end{array}$
\end{tabular}

\section{TITLE AND SUBTITLE}

Electrostatic Noise in the Plasma Environment Around the Shuttle

6. AUTHOR(S)

Boris V. Vayner and Dale C. Ferguson

7. PEAFORMING ORGANIZATION NAME(S) AND ADDRESS(ES)

National Aeronautics and Space Administration

Lewis Research Center

Cleveland, Ohio 44135-3191

9. SPONSORINGMONITORING AGENCY NAME(S) AND ADDRESS(ES)

National Aeronautics and Space Administration

Washington, D.C. 20546-0001
5. FUNDING NUMBERS

WU-233-01-0E

8. PERforming organization REPORT NUMBER

E-9447

10. SPONSORINGMONITORING AGENCY REPORT NUMBER

NASA TM-106856

AIAA-95-1944

11. SUPPLEMENTARY NOTES

Prepared for the 26th Plasmadynamics and Lasers Conference sponsored by the American Institute of Aeronautics and Astronautics, San Diego, Califomia, June 19-22, 1995. Boris V. Vayner, National Research Council-NASA Research Associate at Lewis Research Center, and Dale C. Ferguson, NASA Lewis Research Center. Responsible person, Dale C. Ferguson, organization code 5470, (216) 433-2298.

12a. DISTRIBUTKONAVAILABILTY STATEMENT

12b. DISTRIBUTION CODE

Unclassified - Unlimited

Subject Category 46

This publication is available from the NASA Center for Aerospace Information, (301) 621 -0390 .

13. ABSTRACT (Maximum 200 words)

The Langmuir probe flown as part of the SAMPIE package aboard the space shuttle flight STS-62 was used to determine plasma potential fluctuations in the vicinity of the shuttle. The broadband noise was observed at frequencies $250-20,000$ Hz. Measurements were performed in ram conditions; thus, it seems reasonable to believe that the influence of spacecraft operations on plasma parameters was absolutely negligible. The average spectrum of fluctuations is in agreement with theoretical predictions. The influence on the observed spectra of arcing generated by high negative bias voltages applied to solar cell samples is briefly discussed.

14. SUBJECT TERMS

Plasma turbulence; Langmuir probe; Spectrum; Arcing; Solar cells

17. SECURTY CLASSIFICATION
OF REPORT
Unclassified

NSN 7540-01-280-5500

\author{
18. SECURITY CLASSIFICATION \\ OF THIS PAGE \\ Unclassified
}
19. SECURITY CLASSIFICATION OF ABSTRACT Unclassified

$\mathrm{A02}$

20. LIMTAATION OF ABSTRACT

Standard Form 298 (Rev. 2-89)

Prescribed by ANSI SId. Z39-18 298-102 